\title{
Role of Examples and Interpretation of Results in Developing Multi-Objective Optimization Techniques
}

\author{
Chandra Sen \\ Department of Agricultural Economics, Institute of Agricultural Sciences, Banaras Hindu University, Varanasi, India \\ Email: chandra_sen@rediffmail.com
}

How to cite this paper: Sen, C. (2020) Role of Examples and Interpretation of Results in Developing Multi-Objective Optimization Techniques. American Journal of Operations Research, 10, 138-145. https://doi.org/10.4236/ajor.2020.104010

Received: June 9, 2020

Accepted: July 21, 2020

Published: July 24, 2020

Copyright $\odot 2020$ by author(s) and Scientific Research Publishing Inc. This work is licensed under the Creative Commons Attribution International License (CC BY 4.0).

http://creativecommons.org/licenses/by/4.0/

\begin{abstract}
The paper evaluates the suitability of examples used in developing averaging techniques of multi-objective optimization (MOO). Most of the examples used for proposing these techniques were not suitable. The results of these examples have also not been interpreted correctly. An appropriate example has also been solved with existing and improved averaging techniques of multi-objective optimization.
\end{abstract}

\section{Keywords}

Multi-Objective Optimization, Averaging Multi-Objective Optimization

Techniques, Improved Averaging Multi-Objective Optimization

Techniques

\section{Introduction}

The importance of examples in understanding the mathematical theories or mathematical interpretations is very well recognised. Examples are the principle devices used to illustrate and communicate concepts to the learner. Examples are quite relevant for making any mathematical theory or concept more realistic and acceptable. The present study evaluates the suitability of the examples used in the development of new averaging MOO techniques. After Sen's MOO technique [1], several averaging MOO techniques [2]-[11] have been proposed during last three decades. Many examples have been used for testing the applicability of these techniques. Seven examples used in these MOO techniques have been selected for the present analysis. The presence of conflicts amongst objectives is the main characteristic of an appropriate example. The results of these examples and their interpretations have also been reviewed. The achievement of the objec- 
tives using MOO techniques has been compared with the results of individual optimization. The results of the existing averaging MOO techniques using these examples have not been interpreted correctly. An appropriate example has also been solved using existing and improved averaging MOO techniques [12] for comparison.

\section{Multi-Objective Optimization Techniques}

The mathematical forms of Sen's MOO technique, existing and improved averaging MOO techniques are described as:

Optimize $Z=\left[\operatorname{Max} . Z_{1}\right.$, Max. $Z_{2}, \cdots, \operatorname{Max} . Z_{r}, \operatorname{Min} . Z_{r+1}, \cdots$, Min. $\left.Z_{s}\right]$

Subject to:

$$
A X=b \text { and } X \geq 0
$$

The individual optima are obtained by optimizing each objective separately as:

$$
Z_{\text {optima }}=\left[\theta_{1}, \theta_{2}, \cdots, \theta_{s}\right]
$$

The Sen's Multi-Objective Function [1] is formulated as:

Maximize $Z=\frac{\sum_{j=1}^{r} Z_{j}}{\left|\theta_{j}\right|}-\frac{\sum_{j=r+1}^{s} Z_{j}}{\left|\theta_{r+1}\right|}$

Subject to:

$$
\begin{gathered}
A X=b \text { and } X \geq 0 \\
\theta_{j} \neq 0 \text { for } j=1,2, \cdots, s .
\end{gathered}
$$

where,

$\theta_{j}$ is the optimal value of $f^{\text {th }}$ objective function.

The Multi-Objective Function for the existing averaging MOO technique [2]-[11] is formulated as under:

Maximize $Z=\frac{\sum_{j=1}^{r} Z_{j}}{\left|\theta_{1 a v}\right|}-\frac{\sum_{j=r+1}^{s} Z_{j}}{\left|\theta_{2 a v}\right|}$

Subject to:

$$
\begin{gathered}
A X=b \text { and } X \geq 0 \\
\theta_{j} \neq 0 \text { for } j=1,2, \cdots, s .
\end{gathered}
$$

where,

$\theta_{1 a v}$ is the average of optimal values of the maximization objective functions and

$\theta_{2 a v}$ is the average of optimal values of the minimization objective functions.

An improved averaging MOO technique is also proposed for comparative analysis.

The Multi-Objective function for improved averaging MOO technique [12] is formulated as:

Maximize $Z=\frac{\sum_{j=1}^{r} Z_{j}}{\left|\theta_{1 a v}\right|}-\frac{\sum_{j=r+1}^{s} Z_{j}}{\left|\theta_{2 a v}\right|}$ 
Subject to:

$$
\begin{gathered}
A X=b \text { and } X \geq 0 \\
\theta_{j} \neq 0 \text { for } j=1,2, \cdots, s .
\end{gathered}
$$

\section{Where,}

$\theta_{1 a v}$ is the average value of optimal and sub optimal values of the maximization objective functions and $\theta_{2 a v}$ is the average value of optimal and sub optimal values of the minimization objective functions.

\section{Examples}

The following seven examples used in existing averaging MOO technique are given below:

Example 1: [2] [6]

$$
\begin{gathered}
\text { Max. } Z_{1}=X_{1}+2 X_{2} \\
\text { Max. } Z_{2}=X_{1}
\end{gathered}
$$

Min. $Z_{3}=-2 X_{1}-3 X_{2}$

$$
\operatorname{Min} . Z_{4}=-X_{2}
$$

Subject to:

$$
\begin{gathered}
6 X_{1}+8 X_{2} \leq 48 \\
X_{1}+X_{2} \geq 3 \\
X_{1} \leq 4 \\
X_{2} \leq 3
\end{gathered}
$$

Example 2: [7]

$$
\begin{gathered}
\text { Max. } Z_{1}=\left(3 X_{1}+2 X_{2}+4\right)\left(2 X_{1}+5 X_{2}+3\right) /\left(2 X_{1}+2 X_{2}+2\right)\left(X_{1}+X_{2}+1\right) \\
\text { Max. } Z_{2}=\left(6 X_{1}+4 X_{2}+8\right)\left(6 X_{1}+15 X_{2}+9\right) /\left(3 X_{1}+3 X_{2}+3\right)\left(5 X_{1}+5 X_{2}+5\right) \\
\text { Max. } Z_{3}=\left(12 X_{1}+8 X_{2}+16\right)\left(4 X_{1}+10 X_{2}+6\right) /\left(X_{1}+X_{2}+1\right)\left(4 X_{1}+4 X_{2}+4\right) \\
\text { Min. } Z_{4}=\left(9 X_{1}+6 X_{2}+12\right)\left(-8 X_{1}-20 X_{2}-12\right) /\left(4 X_{1}+4 X_{2}+4\right)\left(2 X_{1}+2 X_{2}+2\right) \\
\text { Min. } Z_{5}=\left(-15 X_{1}+10 X_{2}-20\right)\left(12 X_{1}+30 X_{2}+18\right) /\left(3 X_{1}+3 X_{2}+3\right)\left(6 X_{1}+6 X_{2}+6\right)
\end{gathered}
$$

\section{Subject to:}

$$
\begin{gathered}
6 X_{1}+5 X_{2} \leq 30 \\
2 X_{1}+X_{2} \leq 8 \\
5 X_{1}+9 X_{2} \leq 45
\end{gathered}
$$

Example 3: [3] [4] [5] [11]

$$
\begin{gathered}
\text { Max. } Z_{1}=\left(3 X_{1}-2 X_{2}\right) /\left(X_{1}+X_{2}+1\right) \\
\text { Max. } Z_{2}=\left(9 X_{1}+3 X_{2}\right) /\left(X_{1}+X_{2}+1\right) \\
\text { Max. } Z_{3}=\left(3 X_{1}-5 X_{2}\right) /\left(2 X_{1}+2 X_{2}+2\right) \\
\text { Min. } Z_{4}=\left(-6 X_{1}+2 X_{2}\right) /\left(2 X_{1}+2 X_{2}+2\right)
\end{gathered}
$$




$$
\text { Min. } Z_{5}=\left(-3 X_{1}-X_{2}\right) /\left(X_{1}+X_{2}+1\right)
$$

\section{Subject to:}

$$
\begin{gathered}
X_{1}+X_{2} \leq 2 \\
9 X_{1}+X_{2} \leq 9
\end{gathered}
$$

\section{Example 4: [7]}

Max. $Z_{1}=\left(X_{1}+3 X_{2}+1\right)\left(4 X_{1}+2 X_{2}+2\right) /\left(3 X_{1}+3 X_{2}+3\right)\left(2 X_{1}+2 X_{2}+2\right)$

Max. $Z_{2}=\left(2 X_{1}+6 X_{2}+2\right)\left(12 X_{1}+6 X_{2}+6\right) /\left(5 X_{1}+5 X_{2}+5\right)\left(X_{1}+X_{2}+1\right)$

Max. $Z_{3}=\left(4 X_{1}+12 X_{2}+4\right)\left(20 X_{1}+10 X_{2}+10\right) /\left(4 X_{1}+4 X_{2}+4\right)\left(2 X_{1}+2 X_{2}+2\right)$

Min. $Z_{4}=\left(-6 X_{1}-8 X_{2}-6\right)\left(16 X_{1}+8 X_{2}+8\right) /\left(3 X_{1}+3 X_{2}+3\right)\left(4 X_{1}+4 X_{2}+4\right)$

Min. $Z_{5}=\left(5 X_{1}+15 X_{2}+5\right)\left(-8 X_{1}-4 X_{2}-4\right) /\left(6 X_{1}+6 X_{2}+6\right)\left(X_{1}+X_{2}+1\right)$

Min. $Z_{6}=\left(-3 X_{1}-9 X_{2}-3\right)\left(24 X_{1}+12 X_{2}+12\right) /\left(2 X_{1}+2 X_{2}+2\right)\left(5 X_{1}+5 X_{2}+5\right)$

\section{Subject to:}

$$
\begin{gathered}
2 X_{1}+X_{2} \leq 4 \\
5 X_{1}+2 X_{2} \leq 25
\end{gathered}
$$

Example 5: [3] [11]

$$
\begin{gathered}
\text { Max. } Z_{1}=\left(5 X_{1}+3 X_{2}\right) /\left(X_{1}+X_{2}+1\right) \\
\text { Max. } Z_{2}=\left(9 X_{1}+5 X_{2}\right) /\left(3 X_{1}+3 X_{2}+3\right) \\
\text { Max. } Z_{3}=\left(3 X_{1}-4 X_{2}\right) /\left(X_{1}+X_{2}+1\right) \\
\text { Max. } Z_{4}=\left(3 X_{1}+2 X_{2}\right) /\left(2 X_{1}+2 X_{1}+2\right)
\end{gathered}
$$

\section{Subject to:}

$$
\begin{gathered}
2 X_{1}+4 X_{2} \geq 8 \\
X_{1}+X_{2} \leq 3 \\
X_{1}+2 X_{2} \leq 10 \\
2 X_{1}+X_{2} \leq 5 \\
X_{1} \leq 2
\end{gathered}
$$

Example 6: [8] [10]

$$
\begin{gathered}
\text { Max. } Z_{1}=\left(2 X_{1}+X_{2}+1\right)\left(2 X_{1}+X_{2}+2\right) /\left(2 X_{1}+2 X_{2}+2\right) \\
\text { Max. } Z_{2}=\left(4 X_{1}+2 X_{2}+2\right)\left(6 X_{1}+3 X_{2}+6\right) /\left(3 X_{1}+3 X_{2}+3\right) \\
\text { Max. } Z_{3}=\left(4 X_{1}+2 X_{2}+2\right)\left(6 X_{1}+3 X_{2}+6\right) /\left(6 X_{1}+6 X_{2}+6\right) \\
\text { Min. } Z_{4}=\left(-8 X_{1}-4 X_{2}-4\right)\left(6 X_{1}+3 X_{2}+6\right) /\left(5 X_{1}+5 X_{2}+5\right) \\
\text { Min. } Z_{5}=\left(-4 X_{1}-2 X_{2}-2\right)\left(10 X_{1}+5 X_{2}+10\right) /\left(2 X_{1}+2 X_{2}+2\right)
\end{gathered}
$$

\section{Subject to:}

$$
X_{1}+2 X_{2} \leq 4
$$




$$
3 X_{1}+X_{2} \leq 6
$$

Example 7: [6]

Max. $Z_{1}=X_{1}$

Max. $Z_{2}=2+X_{1}+2 X_{2}$

Max. $Z_{3}=3+X_{2}$

Min. $Z_{4}=-3 X_{2}$

Min. $Z_{5}=-X_{1}-3 X_{2}$

Subject to:

$$
\begin{gathered}
2 X_{1}+3 X_{2} \leq 6 \\
X_{1} \leq 4 \\
X_{1}+2 X_{2} \leq 2
\end{gathered}
$$

\section{Interpretation of the Results}

The solutions of all the above mentioned examples are presented in Table 1.

The solutions of the individual optimizations of all the objectives were unique as given in the $X_{i}$ row. Hence, none of the examples requires the application of any MOO technique. However, all these examples have been solved using Sen's MOO technique and averaging technique. The solutions of MOO techniques were all the same as individual optimization and given in $2^{\text {nd }}$ and $3^{\text {rd }}$ row of $X_{i}$. The values of multi-objective function $Z_{a v}$ and $Z_{\text {sen }}$ were not exactly the same for most of the examples due to difference in the formulation of multi-objective functions. The achievements of the real objectives of the examples have been evaluated for the efficiency of the MOO techniques The values of decision variable $X_{i}$ were exactly same in all the solutions of individual as well as MOO techniques. The MOO techniques with higher values of multi-objective function

Table 1. Individual and multi-objective optimization.

\begin{tabular}{cccccccc}
\hline Example & $\mathbf{1}$ & $\mathbf{2}$ & $\mathbf{3}$ & $\mathbf{4}$ & $\mathbf{5}$ & $\mathbf{6}$ & $\mathbf{7}$ \\
\hline Individual Opt. $\boldsymbol{X}_{\boldsymbol{i}}$ & 4,3 & 0,5 & 1,0 & 0,4 & 2,1 & 2,0 & 0,1 \\
Multi-obj. opt.av. $\boldsymbol{X}_{\boldsymbol{i}}$ & 4,3 & 0,5 & 1,0 & 0,4 & 2,1 & 2,0 & 0,1 \\
Multi-obj. opt.sen $\boldsymbol{X}_{\boldsymbol{i}}$ & 4,3 & 0,5 & 1,0 & 0,4 & 2,1 & 2,0 & 0,1 \\
$Z_{1}$ & 10 & 5.44 & 1.5 & 0.8 & 3.25 & 5.0 & 0 \\
$Z_{2}$ & 4 & 4.35 & 4.5 & 6.2 & 1.92 & 20.0 & 4 \\
$Z_{3}$ & -17 & 21.7 & 0.75 & 13 & 0.5 & 10 & 4 \\
$Z_{4}$ & -3 & -16.3 & -1.5 & -10.4 & 1 & -24 & -3 \\
$Z_{5}$ & & -18.1 & -1.5 & -8.6 & & -50 & -3 \\
$Z_{6}$ & & & & -9.3 & & & \\
$Z_{\text {av. }}$ & 3.39 & 4.35 & 5.2 & $6.25^{*}$ & 8 & 5 & 4.4 \\
$Z_{\text {sen }}$ & 3.39 & 1.0 & 5 & 0.98 & 4 & 5 & 4 \\
\hline
\end{tabular}


were declared superior over the MOO technique with lower values of multi-objective functions in the most of the studies, which is not appropriate. An appropriate example has been solved using the existing and improved MOO techniques.

\section{Appropriate Example}

Further a new example for testing existing and improved averaging MOO techniques is mentioned below:

\section{Example 8:}

$$
\begin{gathered}
\text { Max. } Z_{1}=12500 X_{1}+25100 X_{2}+16700 X_{3}+23300 X_{4}+20200 X_{5} \\
\text { Max. } Z_{2}=21 X_{1}+15 X_{2}+13 X_{3}+17 X_{4}+11 X_{5} \\
\text { Min. } Z_{3}=370 X_{1}+280 X_{2}+350 X_{3}+270 X_{4}+240 X_{5} \\
\text { Min. } Z_{4}=1930 X_{1}+1790 X_{2}+1520 X_{3}+1690 X_{4}+1720 X_{5}
\end{gathered}
$$

\section{Subject to:}

$$
\begin{gathered}
X_{1}+X_{2}+X_{3}+X_{4}+X_{5}=4.5 \\
2 X_{1} \geq 1.0 \\
3 X_{4} \geq 1.5 \\
X_{1}, X_{2}, X_{3}, X_{4}, X_{5} \geq 0
\end{gathered}
$$

The example was solved for achieving each objective and the results are presented in Table 2 of individual optimization matrix. Each column gives the optimal value of the mentioned objective function and suboptimal values of the remaining objective functions. The values of decision variables are given in $X_{i}$ row. All the solutions of individual optimizations are different. None of the solution optimizes all the objective functions simultaneously. The conflicts amongst objective functions are very clear and necessitate the need of multi-objective optimization.

The existing averaging MOP techniques using mean, geometric mean and harmonic mean have been applied for solving the above example. The example was also solved using improved techniques of mean, geometric mean and harmonic mean and the results are presented in Table 3.

The results of multi-objective optimization with existing averaging techniques

Table 2. Individual optimization matrix.

\begin{tabular}{ccccc}
\hline \multirow{2}{*}{ Item } & \multicolumn{4}{c}{ Individual Optimization } \\
\cline { 2 - 5 } & Max. $Z_{1}$ & Max. $Z_{2}$ & Min. $Z_{3}$ & Min. $Z_{4}$ \\
\hline$X_{i}$ & $0.5,3.5,0,0.5,0$ & $4,0,0,0.5,0$ & $0.5,0,0,0.5,3.5$ & $0.5,0,3.5,0.5,0$ \\
$Z_{1}$ & 105,750 & 61,650 & 88,600 & 76,350 \\
$Z_{2}$ & 71.5 & 92.5 & 57.5 & 64.5 \\
$Z_{3}$ & 1300 & 1615 & 1160 & 1545 \\
$Z_{4}$ & 8075 & 8565 & 7830 & 7130 \\
\hline
\end{tabular}


Table 3. Multi-objective optimization.

\begin{tabular}{ccccccc}
\hline & \multicolumn{3}{c}{ Existing Average Techniques } & \multicolumn{3}{c}{ Improved Average Techniques } \\
\cline { 2 - 7 } Item & Mean & $\begin{array}{c}\text { Harmonic } \\
\text { Mean }\end{array}$ & $\begin{array}{c}\text { Geometric } \\
\text { Mean }\end{array}$ & Mean & $\begin{array}{c}\text { Harmonic } \\
\text { Mean }\end{array}$ & $\begin{array}{c}\text { Geometric } \\
\text { Mean }\end{array}$ \\
\hline$X_{i}$ & $0.5,3.5,0,0.5,0$ & $0.5,3.5,0,0.5,0$ & $0.5,3.5,0,0.5,0$ & $0.5,0,0,4,0$ & $0.5,0,0,4,0$ & $0.5,0,0,4,0$ \\
$Z_{1}$ & 105,750 & 105,750 & 105,750 & 99,450 & 99,450 & 99,450 \\
$Z_{2}$ & 71.5 & 71.5 & 71.5 & 78.5 & 78.5 & 78.5 \\
$Z_{3}$ & 1300 & 1300 & 1300 & 1265 & 1265 & 1265 \\
$Z_{4}$ & 8075 & 8075 & 8075 & 7725 & 7725 & 7725 \\
\hline
\end{tabular}

using mean, geometric and harmonic mean are all the same and achieving first objective only. The remaining three objectives are ignored. The value $Z_{1}$ is 105,750 which is the optimal value of first objective. Values of remaining objectives $Z_{2}, Z_{3}$ and $Z_{4}$ are $71.4,1300$, and 8075 respectively which are sub optimal. However all the improved averaging techniques have also generated the unique solution but achieved all the objectives simultaneously. The improved averaging techniques have generated the compromised and more acceptable solutions than the existing averaging techniques.

\section{Conclusion}

The present analysis reveals that the examples used for testing existing averaging MOO techniques in many studies were not suitable for the purpose. The individual optimization revealed that all the examples were with non conflicting objectives and thus unsuitable in the application of MOO technique. The results have also not been interpreted appropriately. The values of multi-objective functions have been considered as achievements of all the objectives which are not correct. The values of basic objectives should have been considered for any conclusion. The study has been extended by adding an appropriate example and improved MOO techniques. The eighth example was found suitable for the validation of existing and improved averaging $\mathrm{MOO}$ techniques. The existing $\mathrm{MOO}$ techniques have been found inefficient in solving MOO problems.

\section{Conflicts of Interest}

The author declares no conflicts of interest regarding the publication of this paper.

\section{References}

[1] Sen, C. (1983) A New Approach for Multi-Objective Rural Development Planning. The Indian Economic Journal, 30, 91-96.

[2] Sulaiman, N.A. and Hamadameen, A.-Q.O. (2008) Optimal Transformation Technique to Solve Multi-Objective Linear Programming Problem (MOLPP). Journal of Kirkuk University-Scientific Studies, 3, 158-168.

[3] Sulaiman, N.A. and Abdulrahim, B.K. (2013) Using Transformation Technique to 
Solve Multi-Objective Linear Fractional Programming Problem. International Journal of Research and Reviews in Applied Sciences, 14, 559-567.

[4] Sulaiman, N.A., Sadiq, G.W. and Abdulrahim, B.K. (2014) New Arithmetic Average Technique to Solve Multi-Objective Linear Fractional Programming: Problem and Its Comparison with Other Techniques International Journal of Research and Reviews in Applied Sciences, 18, 122-131.

[5] Sulaiman, N.A. and Nawkhass, M.A. (2015) Using Short-Hierarchical Method to Solve Multi-Objective Linear Fractional Programming Problems. Journal of Garmian University, 1-15.

[6] Sulaiman, N.A. and Mustafa, R.B. (2016) Using Harmonic Mean to Solve MultiObjective Linear Programming Problems. American Journal of Operations Research, 6, 25-30. https://doi.org/10.4236/ajor.2016.61004

[7] Sulaiman, N.A. and Nawkhass, M.A. (2016) Using Standard Division to Solve Multi-Objective Quadratic Fractional Programming. Journal of Zankoy Sulaimani, 18, 157-163. https://doi.org/10.17656/jzs.10544

[8] Akhtar, H., Modi, G. and Duraphe, S. (2017) An Appropriate Approach for Transforming and Optimizing Multi-Objective Quadratic Fractional Programming Problem. International Journal of Mathematics Trends and Technology, 50, 80-83. https://doi.org/10.14445/22315373/IJMTT-V50P511

[9] Nahar, S. and Alim, Md.A. (2017) A New Statistical Averaging Method to Solve Multi-Objective Linear Programming Problem. International Journal of Science and Research, 6, 623-629.

[10] Huma, A., Geeta, M. and Sushma, D. (2017) Transforming and Optimizing Multi-Objective Quadratic Fractional Programming Problem. International Journal of Statistics and Applied Mathematics, 2, 1-5.

[11] Abdulrahim, B.K. and Abdulla, S.O. (2019) Using Interactive Techniques and New Geometric Average Techniques to Solve MOLFPP. Journal of the University of Garmian, 6. https://doi.org/10.24271/garmian.196363

[12] Sen, C. (2019) Improved Scalarizing Techniques for Solving Multi-Objective Optimization Problems. American Journal of Operational Research, 9, 8-11. 